\begin{tabular}{|c|c|}
\hline Title & Characterization of Campylobacter jejuni DNA gyrase as the target of quinolones \\
\hline Author(s) & $\begin{array}{l}\text { Changkwany eun, Ruchirada; U sui, Masaru; Kongsoi, Siriporn; Y okoyama, Kazumasa; Kim, Hyun; Suthienkul, Orasa; } \\
\text { Changkaew, Kanj ana; Nakaji ima, Chie; T amura, Y Ytaka; Suzuki, Y asuhiko }\end{array}$ \\
\hline Citation & $\begin{array}{l}\text { Journal of infection and chemotherapy : official journal of the Japan Society of Chemotherapy, 21(8), } 604.609 \\
\text { https://doi.org/10.1016/.jiac.2015.05.003 }\end{array}$ \\
\hline Issue Date & $2015-08$ \\
\hline Doc URL & http:/hdl .handle.net/2115/76492 \\
\hline Rights & $\begin{array}{l}\text { () 2015. This manuscript version is made available under the CC-BY-NC-ND } 4.0 \text { license } \\
\text { http://reativecommons.org/icenses/by-nc-nd/4.0/ }\end{array}$ \\
\hline Rights(URL) & https:/creativecommons.org/icenses/by-nc-nd/4.0/ \\
\hline Tyре & article (author version) \\
\hline Additional Information & There are other files related to this item in HUSCAP. Check the above URL. \\
\hline File Information & Changkwanyeun_JIC_Main text_Rev_A ccepted-Final.pdf \\
\hline
\end{tabular}

Instructions for use 


\section{Characterization of Campylobacter jejuni DNA gyrase as the target of}

\section{2 quinolones}

3

4 Ruchirada Changkwanyeun ${ }^{1}$, Masaru Usui ${ }^{2}$, Siriporn Kongsoi ${ }^{1}$, Kazumasa

5 Yokoyama $^{3}$, Hyun Kim ${ }^{4}$, Orasa Suthienkul ${ }^{5,6}$, Kanjana Changkaew ${ }^{1}$, Chie

6 Nakajima $^{1,7}$, Yataka Tamura ${ }^{2}$, Yasuhiko Suzuki ${ }^{1,7, *}$

7

$8 \quad{ }^{1}$ Division of Bioresources, Hokkaido University Research Center for Zoonosis Control,

9 Sapporo, Japan

$10 \quad{ }^{2}$ Laboratory of food microbiology and food safety, Department of health and

11 environmental sciences, School of veterinary medicine, Rakuno Gakuen University,

12 Ebetsu, Japan

$13{ }^{3}$ Central Research Laboratory, Kissei Pharmaceutical Co., Ltd, Azumino, Japan

$14{ }^{4}$ Laboratory of Tuberculosis Control, Department of Bacteriology II, National Institute

15 of Infectious Diseases, Musashi Murayama, Japan

$16 \quad{ }^{5}$ Faculty of Public Health, Thammasat University, Rangsit, Thailand

$17{ }^{6}$ Department of Microbiology, Faculty of Public Health, Mahidol University, Bangkok,

18 Thailand

$19{ }^{7}$ Hokkaido University The Global station for Zoonosis Control, Sapporo, Japan

21 * Corresponding author: Division of Bioresources, Hokkaido University Research

22 Center for Zoonosis Control, Kita 20-Nishi 10, Kita-ku, Sapporo 001-0020, Hokkaido,

23 Japan. Tel: 81-11-706-9503. Fax: 81-11-706-7310. E-mail: suzuki@czc.hokudai.ac.jp. 


\section{Abstract}

2 Quinolones have long been used as the first-line treatment for Campylobacter

3 infections. However, an increased resistance to quinolones has raised public health

4 concerns. The development of new quinolone-based antibiotics with high activity is

5 critical for effective, as DNA gyrase, the target of quinolones, is an essential enzyme for

6 bacterial growth in several mechanisms. The evaluation of antibiotic activity against

7 Campylobacter jejuni largely relies on drug susceptibility tests, which require at least 2

8 days to produce results. Thus, an in vitro method for studying the activity of quinolones

9 against the $C$. jejuni DNA gyrase is preferred. To identify potent quinolones, we

10 investigated the interaction of C. jejuni DNA gyrase with a number of quinolones using

11 recombinant subunits. The combination of purified subunits exhibited DNA

12 supercoiling activity in an ATP dependent manner. Drug concentrations that inhibit

13 DNA supercoiling by $50 \%\left(\mathrm{IC}_{50 \mathrm{~S}}\right)$ of 10 different quinolones were estimated to range

14 from 0.4 (sitafloxacin) to $>100 \mu \mathrm{g} / \mathrm{mL}$ (nalidixic acid). Sitafloxacin showed the highest

15 inhibitory activity, and the analysis of the quinolone structure-activity relationship

16 demonstrated that a fluorine atom at R-6 might play the important role in the inhibitory

17 activity against $C$. jejuni gyrase. Measured quinolone $\mathrm{IC}_{50} \mathrm{~S}$ correlated well with

18 minimum inhibitory concentrations $(R=0.9943)$. These suggest that the in vitro

19 supercoiling inhibition assay on purified recombinant $C$. jejuni DNA gyrase is a useful

20 and predictive technique to monitor the antibacterial potency of quinolones. And

21 furthermore, these data suggested that sitafloxacin might be a good candidate for

22 clinical trials on campylobacteriosis.

24 Key words: DNA gyrase/Quinolones/Campylobacter jejuni 


\section{Introduction}

Campylobacter jejuni infection is one of the most commonly identified

4 bacterial causes of gastroenteritis worldwide, and it occurs more frequently than

5 infections caused by other enteric pathogens. Campylobacter infection causes diarrhea

6 in approximately 400-500 million people globally each year [1, 2]. Most patients with

7 Campylobacter infection develop a self-controlled condition that does not require

8 antibiotics. Nevertheless, an antibiotic treatment is recommended when the

9 Campylobacter infection is severe or affects an immunocompromised host [3].

10 Quinolones are a family of antimicrobials for the treatment of Campylobacter infections

11 in human and animals $[1,2]$. However, the introduction of quinolones in veterinary

12 medicine has been reported to cause an emergence of quinolone-resistant

13 Campylobacter [4, 5, 6]. In fact, quinolone resistance in Campylobacter from food

14 animals is now recognized as an emerging public health problem $[3,7]$. Testing for

15 quinolone susceptibility is essential to provide guidance to physicians and veterinarians on the appropriate treatment for Campylobacter infections. C. jejuni is a slow-growing

17 bacterium that requires microaerophilic conditions and supplemented growth media.

18 Variations in the culture media and the incubation conditions, namely, atmosphere,

19 temperature, and time of incubation, could affect the results of antimicrobial

20 susceptibility tests. Therefore, it is highly desirable to develop a simple and rapid test

21 for quinolone susceptibility in Campylobacter.

Quinolones belong to a family of broad-spectrum synthetic antimicrobials. In

23 bacteria, the target of quinolones are the essential enzymes DNA gyrase and DNA

24 topoisomerase IV, belonging to the bacterial type II topoisomerase. DNA gyrase is 
1 unique in that it catalyzes the negative supercoiling of DNA and is essential for DNA

2 replication, transcription and recombination [8]. On the contrary, topoisomerase IV has

3 a specialized role in chromosome segregation. Complete genome sequencing of $C$.

4 jejuni revealed the lack of genes encoding topoisomerase IV $[9,10,11]$ and thus DNA

5 gyrase turned out to be the sole target of quinolones in Campylobacters. Quinolone

6 inhibit DNA supercoiling by stabilizing the complex between gyrase and the cleaved

7 DNA, interrupting the propagation of the replication fork. When the DNA gyrase

8 cleaves the DNA, the antibiotics prevent relegation of the broken strand, resulting in a

9 quinolone-enzyme-DNA complex that leads to inhibition of DNA replication [12, 13].

10 However, because of increased quinolone resistance in C. jejuni, an in vitro method that

11 would accelerate the identification of more potent quinolones against $C$. jejuni is needed

12 for its treatment and effective control.

13 The DNA gyrase consists of two subunits A (GyrA) and B (GyrB) encoded by

14 gyrA and $g y r \mathrm{~B}$, respectively. In order to measure inhibitory activity against $C$. jejuni, we

15 reconstituted DNA gyrase in vitro, expressed both GyrA and GyrB in Escherichia coli,

16 and used their purified forms to evaluate a group of 10 quinolones.

18 Materials and Methods

19 Reagents

20 Ciprofloxacin (CIP), gatifloxacin (GAT), levofloxacin (LVX), sparfloxacin (SPX),

21 enrofloxacin (ENR) and ofloxacin (OFX) were purchased from LKT Laboratories, Inc.

22 (St. Paul, MN). Oxolinic acid (OXO) and nalidixic acid (NAL) were purchased from

23 Wako Pure Chemicals Ltd. (Tokyo, Japan). Moxifloxacin (MXF) was obtained from

24 Toronto Research Chemicals Inc. (Toronto, Ontario, Canada). Sitafloxacin (SIT) was a 
1 gift from Daiichi Sankyo Pharmaceutical, Co., Ltd. (Tokyo, Japan). Oligonucleotide

2 primers were synthesized by Life Technologies (Carlsbad, CA). A Ni-nitrolotriacetic

3 acid (Ni-NTA) protein purification kit was purchased from Life Technologies.

4 Restriction enzymes were obtained from New England BioLabs, Inc. (Ipswich, MA).

$5 \quad$ Supercoiled and relaxed pBR322 DNA were purchased from John Innes Enterprises

6 Ltd. (Norwich, United Kingdom). A protease inhibitor cocktail (Complete Mini, EDTA

7 free) was purchased from Roche Applied Science (Mannheim, Germany).

\section{$8 \quad$ Bacterial strains and plasmids}

9 Escherichia coli strain TOP-10 (Life Technologies Corp., Carlsbad, CA) was used as

10 the cloning host. The pUC118-HincII/BAP plasmid (Takara Bio, Kyoto, Japan) was

11 used to clone amplified DNA fragments. Escherichia coli strains BL-21 (DE3)/pLysS

12 (Merck KGaA, Darmstadt, Germany) were used for protein expression. Vector plasmid

13 pET-20b (+) (Merck KGaA) was used to construct expression plasmids for C. jejuni

14 proteins GyrA and GyrB.

15 Quinolones susceptibility testing

16 Campylobacter jejuni ATCC33560 was grown on Mueller-Hinton agar (MHA; Oxoid

17 Ltd., Basingstoke, UK), and the minimum inhibitory concentrations (MICs) for this

18 strain were determined by a broth dilution method. Briefly, $1 \mu 1$ of suspension was

19 inoculated into Mueller-Hinton broth (MHB; Oxoid Ltd.) supplemented with 5\%

20 defibrinated sheep blood and containing 2-fold serial dilutions of the quinolone. The

21 microdilution tray was incubated at $37^{\circ} \mathrm{C}$ under microaerophilic conditions $\left(10 \% \mathrm{CO}_{2}\right.$,

$225 \% \mathrm{O}_{2}$, and $85 \% \mathrm{~N}_{2}$ ) for 48 hours. The MIC was predetermined as the lowest

23 concentration of quinolone to cause a complete growth inhibition.

24 Construction of DNA gyrase expression vectors 
1 DNA fragments encoding gyrA and gyr B were amplified by polymerase chain reaction

2 using the primers listed in Table 1 . The reaction mixture $(25 \mu \mathrm{l})$ consisted of

3 primeSTAR GXL buffer $\left(\mathrm{Mg}^{2+}\right.$ plus); $200 \mu \mathrm{M}$ each of dATP, dCTP, dGTP, and dTTP;

410 ng DNA from C. jejuni ATCC33560; 2.0 units of PrimeSTAR GXL DNA

5 polymerase (Takara Bio Inc., Kyoto, Japan); and $0.4 \mu \mathrm{M}$ of each primer. PCR was

6 carried out in an iCycle Thermal Cycler (Bio-Rad Laboratories GmbH, California, US)

7 under the following amplification conditions: pre-denaturation at $98^{\circ} \mathrm{C}$ for $2 \mathrm{~min}, 35$

8 cycles of denaturation at $98^{\circ} \mathrm{C}$ for $10 \mathrm{sec}$, annealing $50{ }^{\circ} \mathrm{C}$ for $10 \mathrm{sec}$, extension $72^{\circ} \mathrm{C}$

9 for $3 \mathrm{~min}$, and a final extension step at $72^{\circ} \mathrm{C}$ for $2 \mathrm{~min}$. The PCR products

10 corresponding to the $2.5-\mathrm{kb}$ gyrA and $2.3-\mathrm{kb} g y r \mathrm{~B}$ fragments were ligated into the

11 pUC118-HincII/BAP plasmid and transformed into E. coli Top10 competent cells,

12 according to the manufacturer's instructions. Recombinant plasmids were recovered

13 from white colonies and digested with Nde I and Xho I, and the obtained DNA

14 fragments were ligated into Nde I-Xho I-digested pET-20b and transformed into E. coli

15 Top10. Recombinant clones were selected from the resistant colonies on Luria-Bertani

16 (LB) agar containing ampicillin $(100 \mu \mathrm{g} / \mathrm{mL})$. The nucleotide sequences of the DNA

17 gyrase genes in the plasmids were analyzed using the ABI Prism BigDye Terminator

18 v3.1 cycle sequencing kit (Applied Biosystems, Foster City, CA). Cycle sequencing

19 products were subsequently analyzed in an ABI PRISM 3130x automated genetic

20 analyzer (Applied Biosystems). The sequences were compared with their respective

21 wild-type sequences using BioEdit software

22 (http://www.mbio.ncsu.edu/bioedit/bioedit.html).

23 Recombinant expression and purification of DNA gyrase 
1 DNA gyrase subunits were expressed and purified as previously described $[14,15,16]$,

2 with modifications. Briefly, expression vectors carrying C. jejuni gyrA and gyrB were

3 transformed to E. coli BL 21(DE3)/pLysS. The transformants were grown in LB

4 medium in the presence of $100 \mu \mathrm{g} / \mathrm{mL}$ ampicillin to the $\log$ phase. Expression of GyrA

5 and GyrB was induced with the addition of $1 \mathrm{mM}$ isopropyl $\beta$-D-thiogalactopyranoside

6 (Wako Pure Chemicals Industries Ltd.), and further incubation was conducted for $16 \mathrm{~h}$

7 at $18{ }^{\circ} \mathrm{C}$. Harvested E. coli was lysed by sonication at $30 \%$ duty cycle, 10 cycles of 40

$8 \mathrm{sec}$ on and $40 \mathrm{sec}$ off using Sonifier 250 (Branson, Danbury, CT). After supernatants

9 were centrifuged $(10000 \times g)$ for $30 \mathrm{~min}$, recombinant DNA gyrase subunits were

10 purified by Ni-NTA resin column chromatography and dialyzed against DNA gyrase

11 dilution buffer (50 mM Tris- $\mathrm{HCl}$ pH 7.5, 100 mM KCl, 2 mM DTT, 1 mM EDTA).

12 Protein fractions were examined by sodium dodecyl sulfate-polyacrylamide gel

13 electrophoresis (SDS-PAGE; Wako Pure Chemicals Industries Ltd.) with a protein

14 molecular weight marker (New England Biolab).

15 DNA supercoiling assay and inhibition by quinolones

16 The DNA supercoiling activity of $C$. jejuni DNA gyrase was assayed by monitoring the

17 conversion of relaxed pBR322 to its supercoiled form. The DNA supercoiling activity

18 was tested with a combination of purified C. jejuni GyrA and GyrB. The reaction

19 mixture consisted of DNA gyrase assay buffer (35 mM Tris-HCl pH 7.5, $24 \mathrm{mM} \mathrm{KCl,} 4$

$20 \mathrm{mM} \mathrm{MgCl}_{2}, 2 \mathrm{mM}$ DTT, $1.8 \mathrm{mM}$ spermidine, $1 \mathrm{mM} \mathrm{ATP,} 6.5 \%$ glycerol, $0.1 \mathrm{mg} / \mathrm{mL}$ of

21 BSA), relaxed pBR322 DNA $(0.3 \mu \mathrm{g})$ with $12.5 \mathrm{nM}$ each of GyrA and GyrB for a total

22 volume of $30 \mu \mathrm{l}$. Reactions were run for $30 \mathrm{~min}$ at $37^{\circ} \mathrm{C}$ and stopped by the addition of

$2330 \mu 1$ of chloroform-isoamyl alcohol (24:1 mixture, v/v) and $3 \mu 1$ of $10 \times$ DNA loading

24 dye. The total reaction mixtures were subjected to electrophoresis in $1 \%$ agarose gel in 
1 Tris-borate-EDTA (TBE) buffer. The gels were run for $1 \mathrm{~h}$ at $80 \mathrm{~mA}$ and stained with

2 ethidium bromide $(0.7 \mu \mathrm{g} / \mathrm{mL})$. The extent of supercoiled DNA was quantified with

3 ImageJ software (http://rsbweb.nih.gov/ij) by comparing with the titration curve drawn

4 using various concentration of supercoiled pBR322 on the same agarose gel. The

5 inhibitory effect of 10 quinolones on DNA gyrase was assessed by determining the drug

6 concentrations required to inhibit the supercoiling activity of the enzyme by $50 \%$

$7 \quad\left(\mathrm{IC}_{50 \mathrm{~s}}\right)$

9 Results

10 Construction and purification of recombinant WT DNA gyrase subunits

11 Full-length gyrA and gyrB of C. jejuni ATCC33560 were inserted downstream of the T7

12 promoter in expression vectors pET-20b $(+)$ for expression as His-tagged recombinant

13 protein, as His-tag has been previously shown not to interfere with the catalytic function

14 of GyrA and GyrB (3). The expression of GyrA and GyrB in E. coli BL21 (ADE3)pLysS

15 by induction with IPTG and subsequent purification by Ni-NTA resin resulted in $2.8 \mathrm{mg}$

16 and $1.3 \mathrm{mg}$ of soluble His-tagged 97-kDa protein of GyrA and 87-kDa protein of GyrB,

17 respectively, from $500 \mathrm{~mL}$ cultures. The high purity (>95\%) of recombinant protein was

18 confirmed by SDS-PAGE (Figure 1C).

19 ATP-dependent DNA supercoiling activities of WT DNA gyrase

20 GyrA and GyrB were examined for DNA supercoiling activity with relaxed pBR322

21 DNA as the substrate in the presence and absence of ATP (Figure 1D). A combination of

22 GyrA and GyrB at 50 ng each of GyrA and GyrB each was sufficient for the conversion

23 of $0.3 \mu \mathrm{g}$ of relaxed plasmid pBR322 DNA to its supercoiled form and was used for all

24 DNA supercoiling experiments. The DNA supercoiling activities were observed in the 
1 presence of ATP and both recombinant DNA gyrase subunits, which confirmed the

2 reconstitution of functional DNA gyrase. No subunit alone exhibited DNA supercoiling

3 activity and no supercoiling activity was observed when ATP was omitted.

$4 \quad$ Inhibition of DNA supercoiling by quinolones

5 The inhibitory effect of 10 quinolones on DNA gyrase was investigated by the

6 quinolone-inhibited DNA supercoiling assay. Each quinolone showed a dose-dependent

7 inhibition and their $\mathrm{IC}_{50}$ s ranged from 0.4 (SIT) to $106.8 \mu \mathrm{g} / \mathrm{mL}$ (NAL), as summarized

8 in Table 2. Two representative data are shown in Figure 1E, and the results for other

9 eight quinolones are presented in the supplementary figure. The MICs of 10 quinolones

10 ranged from 0.0078 to $4 \mu \mathrm{g} / \mathrm{mL}$ (Table 2). Furthermore, the $\mathrm{IC}_{50 \mathrm{~S}}$ and the MICs

11 correlated significantly $(R=0.9943)$, as shown in Figure 2 .

13 Discussion

14 Quinolones, a family of drugs for treating C. jejuni infection, are used in

15 veterinary medicine for both prophylactic and therapeutic purposes [1, 2]. However,

16 there is concern about the use of quinolones in animal production, as their use

17 selectively enriches quinolone-resistant Campylobacter, which can then be transmitted

18 to humans via the food chain [17]. Consequently, CIP- and ENR-resistant

19 Campylobacter strains are widely found in humans and animals, respectively. Hence,

20 the development of new quinolone-based antibiotics with higher activity than CIP and

21 ENR has become critical, as DNA gyrase, the target of quinolones, is an essential enzyme required for bacterial growth in several strains. Efforts have been made to find

23 alternative quinolones for the treatment of $C$. jejuni infections. However, the

24 complicated culturing of $C$. jejuni has been a serious impediment for the study of this 
1 pathogen, particularly the screening of new drugs. Studying the interaction of $C$. jejuni

2 DNA gyrase with quinolones is an important step to understand the quinolone structure-

3 activity relationship and to select those quinolones with good antibacterial activity.

Based on findings of previous studies [14, 16], His-tagged recombinant GyrA

5 and GyrB of $C$. jejuni were expressed and purified to obtain a functional DNA gyrase

6 after reconstitution. The reconstituted DNA gyrase allowed us to examine and compare

7 the inhibitory effect of ten quinolones. The inhibition of DNA supercoiling activities by

8 quinolone was observed in a dose-dependent manner, as previously found in other

9 bacterial DNA gyrase $[18,19,20]$. In the present study, eight quinolones (SIT, CIP,

10 LVX, SPX, GAT, MXF, ENR, and OFX) showed a high activity against $C$. jejuni DNA

11 gyrase, with $\mathrm{IC}_{50} \mathrm{~S}$ of 0.4 to $2.3 \mu \mathrm{g} / \mathrm{mL}$. In contrast, the remaining two quinolones, $\mathrm{OXO}$

12 and NAL, showed a lower inhibitory activity, with $\mathrm{IC}_{50} \mathrm{~S}$ of 15.6 and $106.8 \mu \mathrm{g} / \mathrm{mL}$,

13 respectively (Table 2). Similar results were observed during the quinolone-inhibited

14 DNA supercoiling assay with DNA gyrase from various bacterial species. Indeed,

15 quinolones OXO and NAL weakly inhibited the DNA supercoiling activities of

16 Mycobacterium tuberculosis [21], M. leprae [22] and E. coli [23]. Interestingly, the

17 addition of a fluorine atom at position 6 was the earliest common modification in old

18 quinolones. This single alteration causes an increase in inhibitory activity of more than

1910 fold against DNA gyrase and an improvement in MIC also up to 10 fold [24]. The

20 analysis of the quinolone structure-activity relationship showed that the other eight

21 quinolones shared an additional structural feature: a substituent that consisted of three

22 carbon atoms at R-1. Both of these structures exist in many quinolones.

23 In this study, SIT showed the highest inhibitory activity against $C$. jejuni DNA

24 gyrase with an $\mathrm{IC}_{50}$ of $0.4 \mu \mathrm{g} / \mathrm{mL}$. Analysis of the quinolone structure-activity 
1 relationship showed that SIT has a fluorinate cyclopropyl ring at R-1 while other

2 fluoroquinolones have a cyclopropyl ring or a N1-C8 bridge. Furthermore, the addition

3 of a chloride substituent at R-8 may potentially provide an active compound. A number

4 of previous studies have focused on the in vitro efficacy of SIT on microbes other than

5 Campylobacters. SIT has better activity than other available fluoroquinolones against

6 several enterobacterial species, including CIP-resistant strains [25]. Yokoyama et al.

7 [16] conducted an in vitro assay using recombinant mutant DNA gyrases of M. leprae

8 and showed that SIT has an improved activity against quinolone-resistant M. leprae

9 bearing mutant DNA gyrase. Furthermore, SIT showed higher activity against the

10 recombinant DNA gyrase of quinolone-resistant Enterococcus faecalis with alteration in

11 GyrA and ParC than did other tested fluoroquinolones [26]. SIT belongs to the 4th

12 generation of quinolones that are more effective than CIP against $C$. jejuni strains [27].

13 Thus, SIT might be a promising candidate for the treatment of campylobacteriosis

14 caused by CIP-resistant C. jejuni. Although SIT, now only available in Japan, has been

15 reported to cause mild gastrointestinal disorders as an adverse reaction, our data might

16 encourage its use for C. jejuni infections.

17 A good correlation $(R=0.9943)$ between MICs and $\mathrm{IC}_{50}$ s of quinolones against

18 C. jejuni and its DNA gyrase, respectively, was observed (Figure 2). This result strongly

19 suggested that DNA gyrase inhibition is the major factor in quinolone inhibition of $C$.

20 jejuni. Based on MIC values, the quinolones were classified into the same categories as

21 by $\mathrm{IC}_{50}$ values. However, the $\mathrm{IC}_{50} / \mathrm{MIC}$ diversity ratio ranged from 8 to 51 among

22 quinolones. This proportional diversity between the MICs and the $\mathrm{IC}_{50}$ s has been found

23 in E. coli [23], Streptococcus pneumoniae [28], Mycoplasma pneumoniae [29], M.

24 tuberculosis [21] and M. leprae [22], and might be due to differences in cell-permeating 
1 properties and accumulation in distinct quinolones [30]. As shown in Table $3, \mathrm{IC}_{50}$ s of

2 quinolones against C. jejuni and E. coli DNA gyrase were lower [23] than those against

3 S. pneumoniae [28], M. pneumoniae [29], M. tuberculosis [21], and M. leprae [22].

4 These data suggested a stronger interaction of quinolones with C. jejuni and E. coli

5 DNA gyrase than with DNA gyrase from other bacteria. Moreover, the analysis of

6 QRDR sequences showed that E. coli has highly identical QRDR sequences to C. jejuni.

7 In E. coli, substitutions of several amino acids in the GyrA have been shown to be

8 important with regard to quinolone resistance. The most frequently occurring

9 substitution was the replacement of serine 83 . Substitution of serine 83 with leucine or

10 tryptophan has been shown to confer a high-level quinolone resistance in both clinical

11 isolates and laboratory-derived E. coli resistant mutants [31]. The alignment of 40

12 amino acid sequences of C. jejuni GyrA QRDR with analogous sequences from E. coli,

13 S. pneumoniae, M. pneumoniae, M. tuberculosis, and M. leprae is shown in Figure 3, in

14 which threonine 86 (indicated by arrow head) in C. jejuni is analogous to amino acid 83

15 in E. coli GyrA, while those at an equivalent position in GyrA of S. pneumoniae, $M$.

16 pneumoniae, M. tuberculosis, and M. leprae were serine, methionine, alanine, and

17 alanine, respectively. From these results it can be inferred that amino acid residues at an

18 equivalent position to threonine 86 in C. jejuni may be the cause of the increased

19 quinolone resistance of mycobacterial DNA gyrase. In contrast, S. pneumoniae DNA

20 gyrase with serine at the same position showed intrinsic resistance to quinolone. The

21 amino acids in QRDR that are distinct between bacteria species may contribute to

22 various intrinsic susceptibilities.

23 An early study by Han et al. [32] demonstrated the inhibitory activity of a

24 fluoroquinolone, CIP, against C. jejuni DNA gyrase and showed the minimum effective 
1 concentration (MEC) as $32 \mu \mathrm{g} / \mathrm{mL}$. The extremely high concentration of DNA gyrase

2 used in their study, $300 \mathrm{nM}$, comparing to our study (12.5 nM) might be the cause of the

3 discrepancy with our result ( $\mathrm{IC}_{50}=1.0 \mu \mathrm{g} / \mathrm{mL}$ ). Further, the quality or specific activity

4 of the DNA gyrase used in our study might have been much higher than that used in

5 theirs. These data clearly exhibited the advantage of the usage of recombinant DNA

6 gyrase with high activity as produced in our study.

7 In conclusion, we have succeeded in producing and purifying C. jejuni DNA

8 gyrase, which is the sole target of quinolones. Based on the determination of the

9 inhibition activity of quinolones on recombinant $C$. jejuni DNA gyrase, we identified

10 SIT as a promising quinolone for the treatment of campylobacteriosis. The results of

11 this study suggested that the in vitro supercoiling inhibition assay may be a useful and

12 predictive technique to monitor the antibacterial potency of quinolones.

14 Conflict of Interest: There is no conflict of interest to be declared.

16 Acknowledgements

17 This work was supported by a Department of Microbiology Grant; the China

18 Medical Board; the Faculty of Public Health; Mahidol University; the National

19 Development of Science and Technology, Ministry of Science and Technology,

20 Bangkok, Thailand to OS; J-GRID; the Japan Initiative for Global Research Network on

21 Infectious Diseases from the Ministry of Education, Culture, Sports, Science, and

22 Technology, Japan (MEXT); and the Global Center of Excellence (GCOE) Program,

23 "Establishment of International Collaboration Centers for Zoonosis Control” from

24 MEXT to YS. 


\section{References}

3 [1] Allos BM. Campylobacter jejuni infection: update on emerging issues and trends.

$4 \quad$ Clin Infect Dis. 2001;32:1201-6.

5 [2] Ruiz-Palacios GM. The health burden of Campylobacter infection and the impact of

6 antimicrobial resistance: playing chicken. Clin Infect Dis. 2007;44:701-3.

7 [3] Engberg J, Aarestrup FM, Taylor DE, Gerner-Smidt P, Nachamkin I. Quinolone and 8 macrolide resistance in Campylobacter jejuni and C. coli: resistance mechanisms

9 and trends in human isolates. Emerg Infect Dis. 2001;7:24-34.

10 [4] Endtz HP, Ruijs GJ, van Klingeren B, Jansen WH, van der Reyden T, Mouton RP.

11 Quinolone resistance in Campylobacter isolated from man and poultry following

12 the introduction of fluoroquinolones in veterinary medicine. J Antimicrob

13 Chemother. 1991;27:199-208.

14 [5] Luber P, Wagner J, Hahn H, Bartelt E. Antimicrobial resistance in Campylobacter 15 jejuni and Campylobacter coli strains isolated in 1991 and 2001-2002 from poultry 16 and human in Berlin, Germany. Antimicrob Agents Chemother. 2003;47:3825-30.

17 [6] Saenz Y, Zaraga M, Lantero M, Gastanares MJ, Baquero F, Torres C. Antibiotic 18 resistance in Campylobacter strains isolated from animals, foods, and humans in 19 Spain in 1997-1998. Antimicrob Agents Chemother. 2000;44:267-71.

20 [7] Smith KE, Besser JM, Hedberg CW, Leano FT, Bender JB, Wicklund JH, et al. 21 Quinolone-resistant Campylobacter jejuni infections in Minnesota, 1992-1998. N $22 \quad$ Engl J Med. 1999;340:1525-32. 
1 [8] Oyamada Y, Yamagishi J, Kihara T, Yoshida H, Wachi M, Ito H. Mechanism of

2 inhibition of DNA gyrase by ES-1273, a novel DNA gyrase inhibitor. Microbiol

3 Immunol. 2007;51:977-84.

4 [9] Bachoual R, Ouabdesselam S, Mory F, Lascols C, Soussy CJ, Tankovic J. Single or

5 double mutational alterations of $g y r \mathrm{~A}$ associated with fluoroquinolone rsistance in

6 Campylobacter jejuni and Campylobacter coli. Microb Drug Resist. 2001;7:257-61.

7 [10] Luo N, Sahin O, Lin J, Michel LQ, Zhang Q. In vivo selection of Capylobacter

8 isolates with high levels of fluoroquinolone resistance associated with gyrA

9 mutation and the functions of the CmeABC efflux pump. Antimicrob Agents

$10 \quad$ Chemother. 2003;47:390-4.

11 [11] Parkhill J, Wren BW, Mungall K, Ketley JM, Churcher C, Basham D et al. The

12 genome sequence of the food-borne pathogen Campylobacter jejuni reveals

13 hypervariable sequences. Nature. 2000;403:665-8.

14 [12] Drlica K, Zhao X. DNA gyrase, topoisomerase IV, and the 4-quinolones. Microbiol 15 Mol Biol Rev. 1997;61:377-92.

16 [13] Hawkey PM. Mechanism of quinolone action and microbial response. J

17 Antimicrob Chemother. 2003;51:29-35.

18 [14] Kim H, Nakajima C, Yokoyama K, Rahim Z, Kim Y-U, Oguri H et al. Impact of

19 the E540V amino acid substitution in GyrB of Mycobacterium tuberculosis on

20 quinolone resistance. Antimicrob Agent Chemother. 2011;55:3661-7.

21 [15] Matrat S, Cambu SE, Jarlier V, Aubry A. Are all the DNA gyrase mutation found 22 in Mycobacterium leprae clinical strain involved in resistance to fluoroquinolone?

23 Antimicrob. Agents Chemother. 2008;52:745-7. 
1 [16] Yokoyama K, Kim H, Mukai T, Matsuoka M, Nakajima C, Suzuki Y. Amino acid

2 substitutions at position 95 in GyrA can add fluoroquinolone resistance to

3 Mycobacterium leprae. Antimicrob Agents Chemother. 2012;56:697-702.

4 [17] Luangtongkum T, Jeon B, J. Han J, Plummer P, Logue CM, Zhang Q. Antibiotic

5 resistance in Campylobacter: emergence, transmission and persistence. Future

$6 \quad$ Microbiol. 2009;4:189-200.

7 [18] Blanche F, Cameron B, Bernard FX, Maton L, Manse B, Ferrero L et al.

8 Differential behaviors of Staphylococcus aureus and Escherichia coli type II DNA

9 topoisomerase. Antimicrob Agents Chemother. 1996;40:2714-20.

10 [19] Hooper DC, Wolfson JS, Ng EY, Swartz MN. Mechanisms of action of and 11 resistance to ciprofloxacin. Am J Med. 1987;82:12-20.

[20] Pan XS, Fisher LM. Targeting of DNA gyrase in Streptococcus pneumoniae by sparfloxacin: selective targeting of gyrase or topoisomerase IV by quinolones.

[21] Aubry A, Pan XS, Fisher LM, Jarlier V, Cambau E. Mycobacterium tuberculosis DNA Gyrase: Interaction with quinolones and correlation with antimycobacterial drug activity. Antimicrob. Agents Chemother. 2004;48:1281-8.

[22] Matrat S, Petrella S, Cambau E, Sougakoff W, Jarlier V, Aubry A. Expression and purification of an active form of the Mycobacterium leprae DNA gyrase and its inhibition by quinolones. Antimicrob Agents Chemother. 2007;51:1643-8.

[23] Yoshida H, Nakamura M, Bogaki M, Ito H, Kojima T, H. Hattori H et al. Mechanism of action of quinolones against Escherichia coli DNA gyrase. Antimicrob Agents Chemother. 1993;37:839-45. 
1 [24] Andersson MI, MacGowan AP. Development of the quinolones. J Antimicrob

$2 \quad$ Chemother. 2003;51:1-11.

3 [25] Milatovic D, Schmitz FJ, Brisse S, Verhoef J, Fluit AC. In vitro activities of

4 sitafloxacin (DU-6859a) and six other fluoroquinolones against 8,796 clinical

5 bacterial isolates. Antimicrob Agents Chemother. 2000;44:1102-7.

6 [26] Onodera Y, Okuda J, Tanaka M, Sato K. Inhibitory activities of quinolones against

$7 \quad$ DNA gyrase and Topoisomerase IV of Enterococcus faecalis. Antimicrob Agents

$8 \quad$ Chemother. 2002;46:1800-4.

9 [27] Lehtopolku M, Hakanen AJ, Siitonen A, Huovinen P, Kotilainen P. In vitro

10 activities of 11 fluoroquinolones against 226 Campylobacter jejuni strains isolated

11 from Finnish patients, with special reference to ciprofloxacin resistance. J

12 Antimicrob Chemother. 2005;56:1134-8.

13 [28] Morrissey I, George J. Activities of fluoroquinolones against Streptococcus

14 pneumoniae type II topoisomerases purified as recombinant proteins. Antimicrob

15 Agents Chemother. 1999;43:2579-85.

16 [29] Nakatani M, Mizunaga S, Takahata M, Nomura N. Inhibitory activity of

17 garenoxacin against DNA gyrase of Mycoplasma pneumoniae. J Antimicrob

18 Chemother. 2012;67:1850-2.

19 [30] Jarlier V, Nikaido H. Mycobacterial cell wall: structure and role in natural

20 resistance to antibiotics. FEMS Microbiol Lett. 1994;123:11-8.

21 [31] Yoshida H, Bogaki M, Nakamura M, Nakamura S. Quinolone resistance-

22 determining region in the DNA gyrase gyrA gene of Escherichia coli. Antimicrob

23 Agents Chemother. 1990;34:1271-2. 
[32] Han J, Wang Y, Sahin O, Shen Z, Guo B, Shen J et al. A fluoroquinolone resistance associated mutation in gyrA affects DNA supercoiling in Campylobacter jejuni. Front Cell Infect Microbiol. 2012;2:21.

4 


\section{Figure legends}

2 Figure 1. Expression and characterization of recombinant DNA gyrase.

3 Pannel A; Schematic representation of the construction of expression plasmids for GyrA

4 and B. Pannel B; Expression of gyr $A$ and $B$ with His-Tag are controlled by T7 promoter

5 in the expression vector pET20b. Pannel C; His-tagged proteins were overexpressed by

6 an E. coli expression system and purified by nickel resin chromatography.

7 Approximately $300 \mathrm{ng}$ of each protein was loaded on a 5-20\% gradient polyacrylamide

8 gel. Following electrophoresis, proteins were stained with Quick CBB. Lanes: M,

9 protein marker (sizes are indicated at the left in kilo-Daltons); 1, GyrA; 2, GyrB. Pannel

10 D; Reconstitution of ATP-dependent DNA supercoiling activity was confirmed.

11 Relaxed pBR322 DNA $(0.3 \mu \mathrm{g})$ was incubated with DNA gyrase reconstituted with

$1212.5 \mu \mathrm{M}$ each of GyrA and GyrB in the presence or absence of $1 \mathrm{mM}$ ATP. The

13 reactions were stopped, and the DNA products were analysed by electrophoresis in 1\%

14 agarose gels. Lanes: 1, relaxed pBR322 DNA; 2, relaxed pBR322 and both recombinant

15 GyrA and GyrB; 3, relaxed pBR322 and GyrB only; 4, relaxed pBR322 and GyrA only;

16 5, absence of ATP. R and SC, relaxed and supercoiled pBR322 DNA, respectively.

17 Pannel E; Inhibitory activity of (A) SIT and (B) NAL on the supercoiling activities of

18 C. jejuni DNA gyrase were investigated. Relaxed pBR322 DNA $(0.3 \mu \mathrm{g})$ was incubated

19 with $12.5 \mu \mathrm{M}$ each of GyrA and GyrB in the presence of the indicated amounts $(\mu \mathrm{g} / \mathrm{ml})$

20 of both quinolones. The reactions were stopped and the DNA products were analyzed

21 by electrophoresis in 1\% agarose gels. $\mathrm{R}$ and $\mathrm{SC}$ denote relaxed and supercoiled

22 pBR322 DNA, respectively. 
1 Figure 2. Correlation between quinolone inhibition of $C$. jejuni gyrase $\left(\mathrm{IC}_{50 \mathrm{~s}}\right.$ for DNA

2 supercoiling) and quinolone MICs for C. jejuni. $R$ is the correlation coefficient. SIT,

3 sitafloxacin; GAT, gatifloxacin; MXF, moxifloxacin; SPX, sparfloxacin; ENR,

4 enrofloxacin; CIP, ciprofloxacin; LVX, levofloxacin; OFX, ofloxacin; OXO, oxolinic

5 acid; NAL, nalidixic acid.

6

7 Figure 3. Alignment of amino acid sequences of GyrA QRDR. The identity with the

8 sequence from C. jejuni is represented. An asterisk, a colon and a dot indicates positions

9 which have a single, fully conserved residue, conservation between groups of strongly

10 similar properties and conservation between groups of weakly similar properties,

11 respectively. The numbering system used is that for C. jejuni gyrA.

12 


\section{Changkwanyenun et al. Fig. 1}

A

Primers R-5 \& R-36
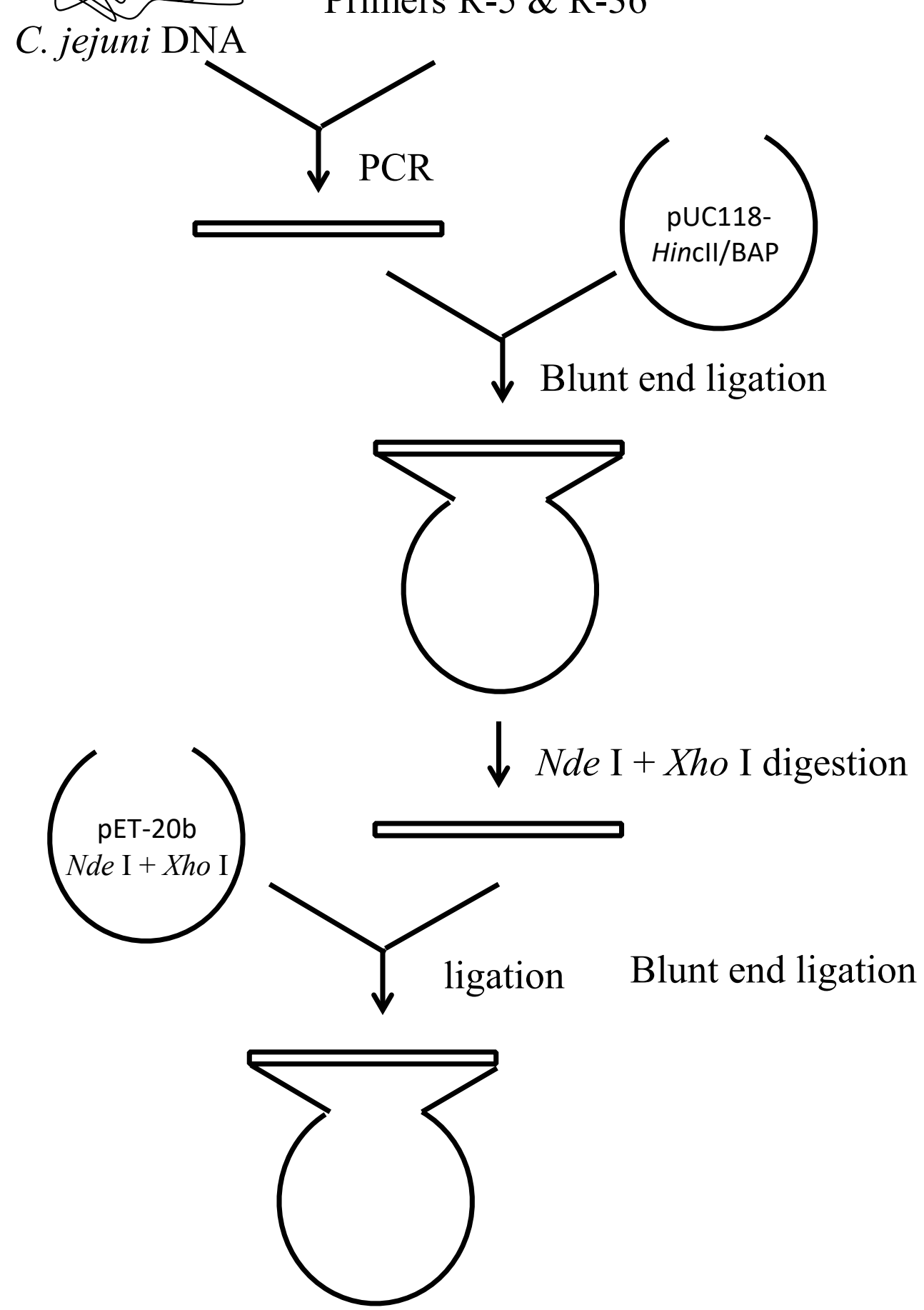

B

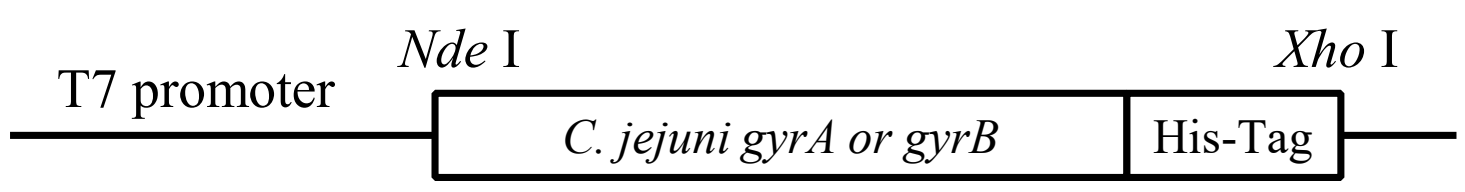

$\mathrm{C}$

$\begin{array}{rlll}\mathrm{kDa} & \mathrm{M} & 1 & 2 \\ 175 & & & \end{array}$

80

58

46

$\mathbf{E}$

(a)

SIT conc. $(\mu \mathrm{g} / \mathrm{ml})$

\begin{tabular}{llllll}
\hline GyrA - & + & - & + & + \\
GyrB - & + & + & - & + \\
ATP - & + & + & + & - \\
DNA + & + & + & + & + \\
\hline
\end{tabular}

$\mathrm{D}$

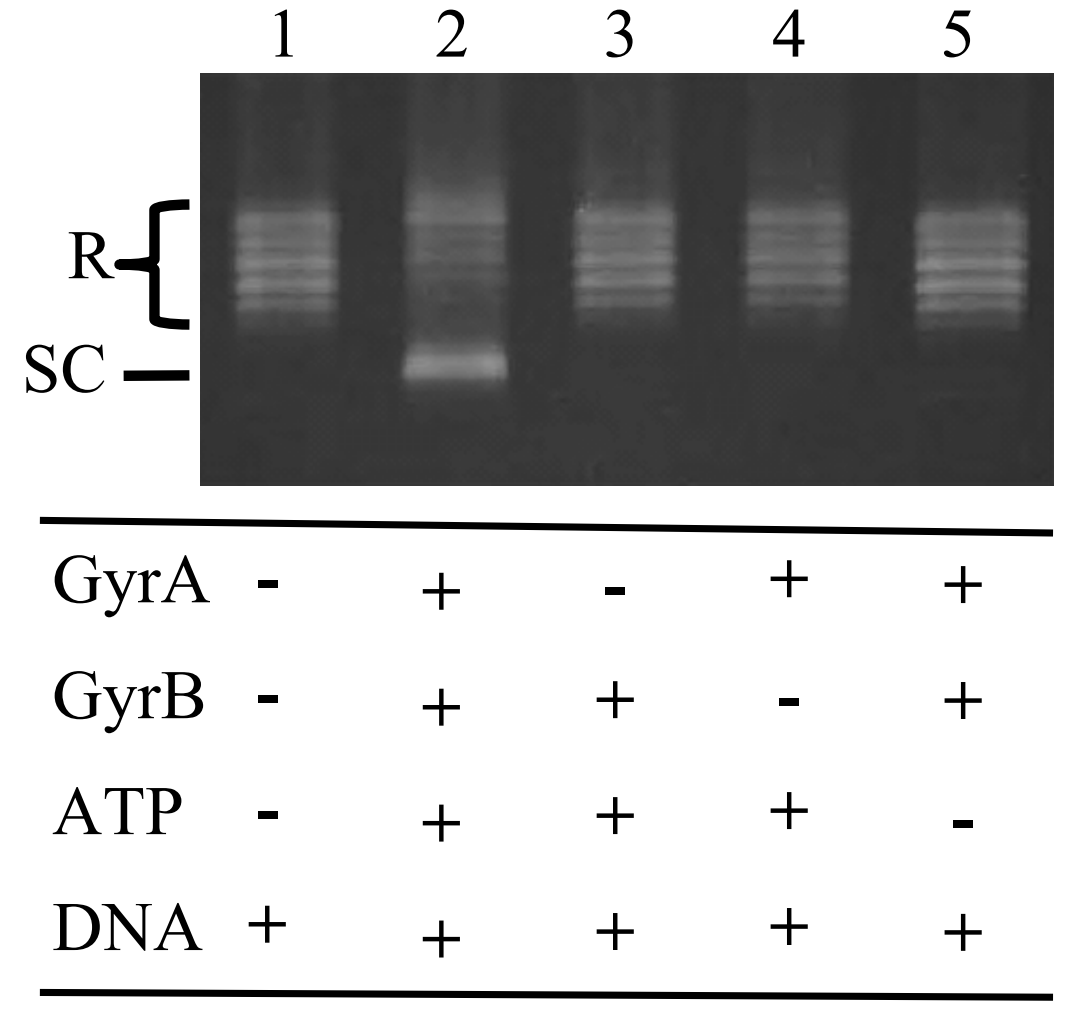
$\begin{array}{llllllllll}0 & 0.08 & 0.16 & 0.31 & 0.62 & 1.25 & 2.5 & 5 & 10 & 20\end{array}$

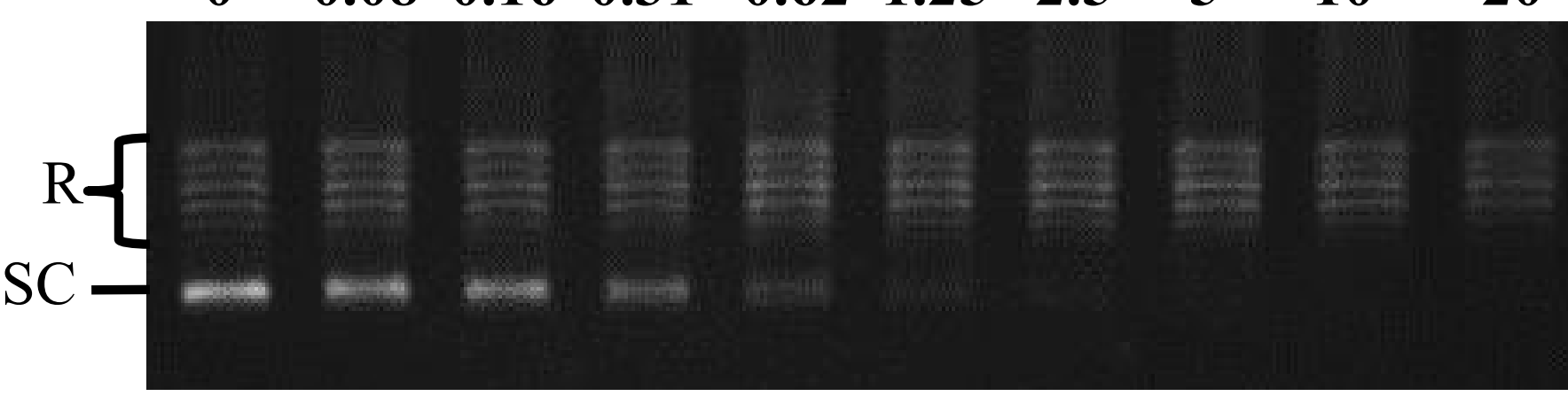

(b)

NAL conc. $(\mu \mathrm{g} / \mathrm{ml})$

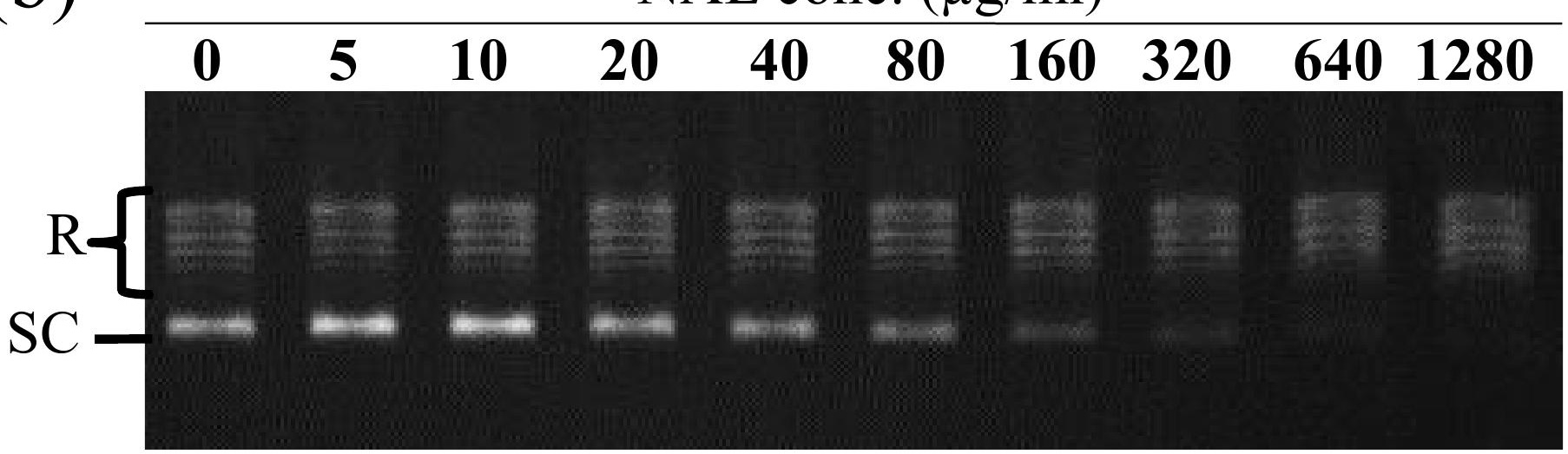


Changkwanyenun et al. Fig. 2

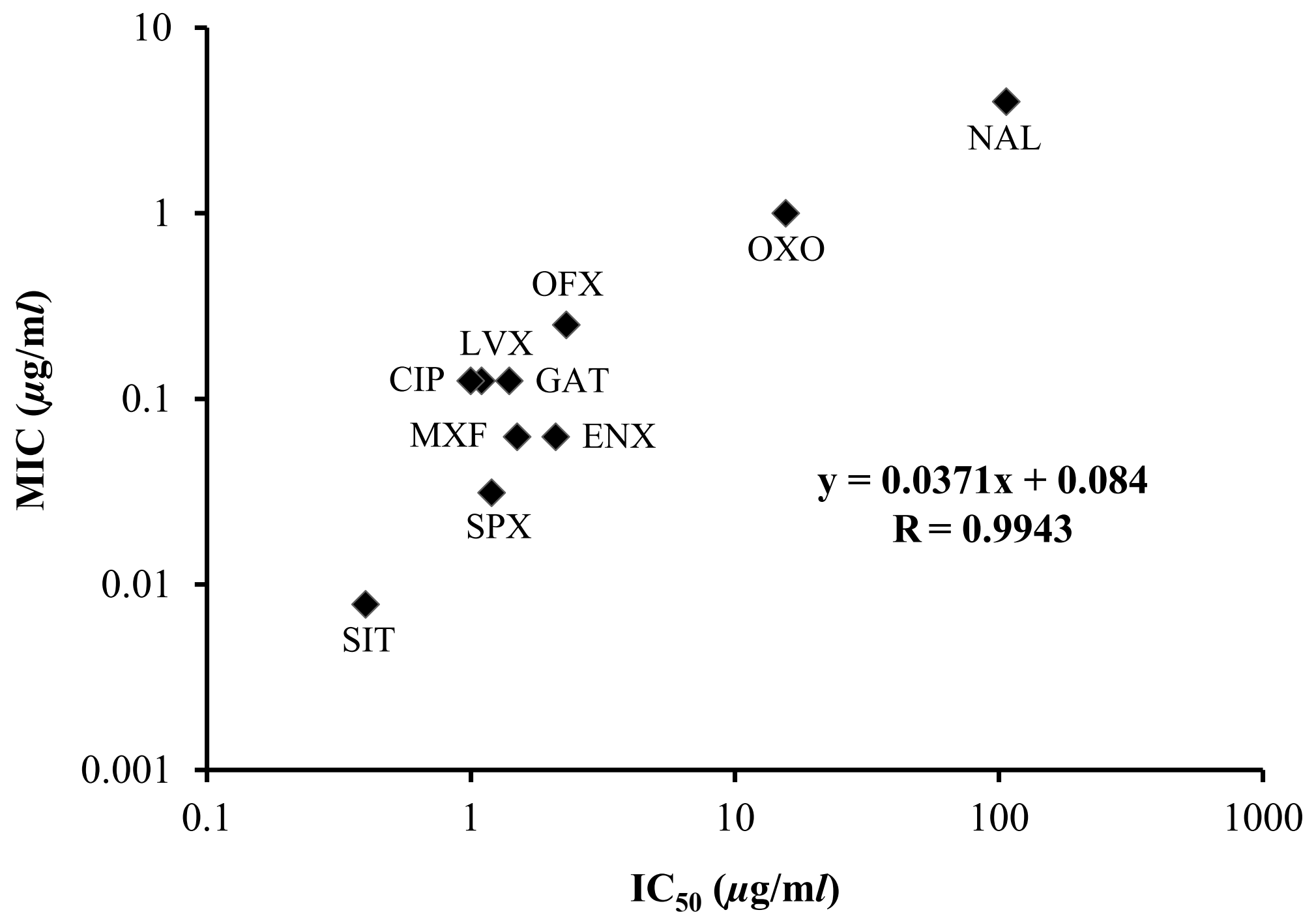




\section{Changkwanyenun et al. Figure 3}

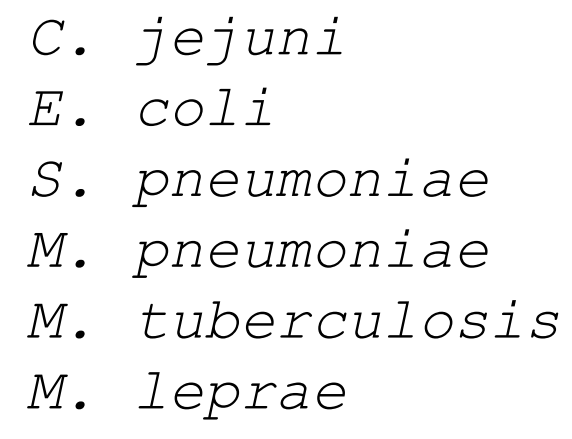


Table 1. Oligonucleotide sequences of primers used for PCR

\begin{tabular}{|c|c|c|}
\hline Primers & Sequence (nucleotide position), underlined element(s) & Remarks \\
\hline R-5 & 5'-CCCATATGGAGAATATTTTTAGCAAAG-3' (1-22), Nde I site & gyr A Foward \\
\hline $\mathrm{R}-36$ & 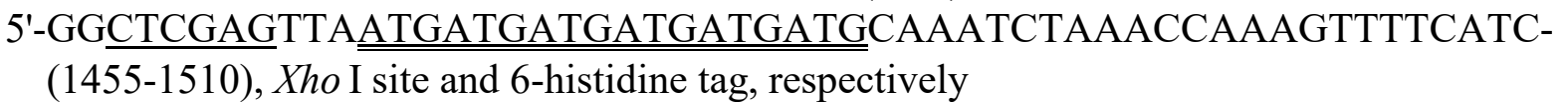 & gyr A Reverse \\
\hline $\mathrm{R}-1$ & 5'-CCCATATGCAAGAAAATTACGGTGC-3' (1-25), Nde I site & gyr B Forward \\
\hline $\mathrm{R}-47$ & $\begin{array}{l}\text { 5'-GGCTCGAGTTA ATGATGATGATGATGATGCACATCCAAATGCTTTACATC-3' } \\
(2177-2230), \text { Xho I site and 6-histidine tag, respectively }\end{array}$ & gyr B Reverse \\
\hline
\end{tabular}

* Single underlines denote the restriction endonuclease recognition sequences.

** Double underlines denote the coding sequences for His hexamer. 
Table 2. Structure features, $\mathrm{IC}_{50} \mathrm{~s}$ and $\mathrm{MICs}$ of quinolones against $C$. jejuni

\begin{tabular}{|c|c|c|c|c|c|c|c|}
\hline \multirow{2}{*}{ Quinolones } & \multicolumn{5}{|c|}{ Substituents } & \multirow{2}{*}{$\begin{array}{c}\mathrm{IC}_{50} \\
(\mu \mathrm{g} / \mathrm{m} l)\end{array}$} & \multirow{2}{*}{$\begin{array}{c}\mathrm{MIC} \\
(\mu \mathrm{g} / \mathrm{m} l)\end{array}$} \\
\hline & $\mathrm{R}-1^{\mathrm{a})}$ & $\mathrm{R}-5^{\mathrm{a})}$ & $\mathrm{R}-6^{\mathrm{a})}$ & $\mathrm{R}-7^{\mathrm{a})}$ & $\mathrm{R}-8^{\mathrm{a})}$ & & \\
\hline SIT & fluorocyclopropyl & $\mathrm{H}$ & $\mathrm{F}$ & Amino azaspiroheptan & $\mathrm{C}-\mathrm{Cl}$ & 0.4 & 0.0078 \\
\hline CIP & Cyclopropyl & $\mathrm{H}$ & $\mathrm{F}$ & Piperazine & $\mathrm{C}-\mathrm{H}$ & 1.0 & 0.125 \\
\hline LVX & Bridge N1-C8 & $\mathrm{H}$ & $\mathrm{F}$ & methylpiperazin & Bridge N1-C8 & 1.1 & 0.125 \\
\hline SPX & Cyclopropyl & Amino & $\mathrm{F}$ & dimethylpiperazin & $\mathrm{C}-\mathrm{F}$ & 1.2 & 0.0312 \\
\hline GAT & Cyclopropyl & $\mathrm{H}$ & $\mathrm{F}$ & Piperazine & C-methoxy & 1.4 & 0.125 \\
\hline MXF & Cyclopropyl & $\mathrm{H}$ & $\mathrm{F}$ & diazabicyclo nonan & C-methoxy & 1.5 & 0.0625 \\
\hline ENX & Ethyl & $\mathrm{H}$ & $\mathrm{F}$ & Piperazine & $\mathrm{N}$ & 2.1 & 0.0625 \\
\hline OFX & Bridge N1-C8 & $\mathrm{H}$ & $\mathrm{F}$ & methylpiperazin & Bridge N1-C8 & 2.3 & 0.25 \\
\hline OXO & Ethyl & $\mathrm{H}$ & Bridge C6-C7 & Bridge C6-C7 & $\mathrm{C}-\mathrm{H}$ & 15.6 & 1.0 \\
\hline NAL & Ethyl & $\mathrm{H}$ & $\mathrm{H}$ & Methyl & $\mathrm{N}$ & 106.8 & 4.0 \\
\hline
\end{tabular}

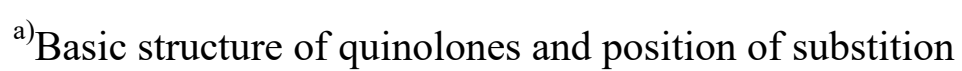<smiles>[R6]c1c([R8])c([R8])c2c(c1[R8])c(=O)cc(C(=O)O)n2[R1]</smiles> 
Table 3. $\mathrm{IC}_{50} \mathrm{~s}$ and MICs $(\mu \mathrm{g} / \mathrm{ml})$ of quinolones inhibiting various DNA gyrases

\begin{tabular}{|c|c|c|c|c|c|c|c|c|c|c|c|c|}
\hline & \multicolumn{2}{|c|}{ C. jejuni } & \multicolumn{2}{|c|}{ E. coli ${ }^{\text {a }}$} & \multicolumn{2}{|c|}{ S. pneumoniae ${ }^{\text {b }}$} & \multicolumn{2}{|c|}{ M. pneumoniae ${ }^{\mathrm{c}}$} & \multicolumn{2}{|c|}{ M. tuberculosis ${ }^{\mathrm{d}}$} & \multicolumn{2}{|c|}{ M. leprae ${ }^{\mathrm{e}}$} \\
\hline & $\mathrm{IC}_{50}$ & MIC & $\mathrm{IC}_{50}$ & MIC & $\mathrm{IC}_{50}$ & MIC & $\mathrm{IC}_{50}$ & MIC & $\mathrm{IC}_{50}$ & MIC & $\mathrm{IC}_{50}$ & $\mathrm{MIC}^{\prime}$ \\
\hline SIT & 0.4 & 0.0078 & ND & ND & 2 & 0.005 & ND & ND & 2.5 & 0.25 & 1 & 25 \\
\hline CIP & 1 & 0.125 & ND & ND & 96 & 0.2 & ND & ND & 3.5 & 0.5 & 3.5 & $>150$ \\
\hline LVX & 1.1 & 0.125 & ND & ND & 54 & 0.1 & 47.5 & 0.5 & 5 & 0.5 & 7 & ND \\
\hline SPX & 1.2 & 0.0312 & 0.39 & 0.0125 & 114 & 0.15 & ND & ND & 2 & 0.25 & 5 & 15 \\
\hline GAT & 1.4 & 0.125 & ND & ND & ND & ND & 5.71 & 0.125 & 3 & 0.12 & 2 & ND \\
\hline MXF & 1.5 & 0.0625 & ND & ND & ND & ND & 7.44 & 0.0625 & 4.5 & 0.5 & 2 & 150 \\
\hline ENR & 2.1 & 0.0625 & ND & ND & ND & ND & ND & ND & ND & ND & ND & ND \\
\hline OFX & 2.3 & 0.25 & ND & ND & 88 & 0.3 & ND & ND & 10 & 1 & 10 & 150 \\
\hline $\mathrm{OXO}$ & 15.6 & 1 & 3.13 & 0.39 & ND & ND & ND & ND & 300 & 32 & 170 & ND \\
\hline NAL & 106.8 & 4 & 50 & 3.13 & ND & ND & ND & ND & 1100 & 128 & 300 & ND \\
\hline
\end{tabular}

a Data from Yoshida et al. (23)

b Data from Morrissey et al. (28)

c Data from Nakatani et al. (29)

d Data from Aubry et al. (21)

e Data from Matrat et al. (22)

f Data from animal experiments using a mouse model 